\title{
A new linear method to find the congestion hyperplane in DEA
}

\author{
M. Ebrahimzade Adimi ${ }^{1}$ - M. Rostamy-Malkhalifeh ${ }^{1}$ (D $\cdot$ F. Hosseinzadeh Lotfi ${ }^{1} \cdot$ R. Mehrjoo $^{2}$
}

Received: 14 September 2018 / Accepted: 30 January 2019 / Published online: 13 February 2019

(c) The Author(s) 2019

\begin{abstract}
DEA is the way of evaluating the performance of decision-making units on the basis of the degree of efficiency. Unfortunately, congestion has been known as a technical inefficiency for at least three decades just because of the lack of determining the congestion border. In this article, we have introduced the concept of the congestion hyperplane without considering the efficiency value. This has considerably reduced the calculation, and the congestion border has been determined. In addition, the existence of this hyperplane is ascertained. For this purpose, we determine the BCC-efficient DMUs. The normal vector of the hyperplane is denoted by these values. This hyperplane can pass from any of the BCC-efficient DMUs. Next, we have shown that the previous congestion methods are covered and improved by this hyperplane.
\end{abstract}

Keywords Data envelopment analysis (DEA) $\cdot$ Congestion $\cdot$ Hyperplane $\cdot$ Linear programming $\cdot$ Decision-making units (DMU)

\section{Introduction}

DEA is a nonparametric mathematical method that is used to evaluate the performance of a set of decision-making units. Congestion occurs when one or more input(s) is/are increased to reduce one or more output(s) without making changes in the other inputs and outputs. Grosskopf and Fare [8] proposed an executable form and studied the related DEA models (Model: FGL) to evaluate the performance of the product. Later, Cooper, Tomston, and Trall (CTT) introduced another model for the study of congestion. Cooper [6] compared these two models using numerical examples. Cooper [4] proposed another theory in which the two-step calculation is combined in CTT. Brackets [2] suggested CTT models to examine the relationship between employment and output in order to increase employment in the manufacturing industries of China [7]. Cooper [3] studied the congestion management in Chinese industry and showed how evaluating managerial inefficiency caused an increase in the output size without reducing employment in the textile and

M. Rostamy-Malkhalifeh

mohsen_rostamy@yahoo.com

1 Department of Mathematics, Science and Research Branch, Islamic Azad University, Tehran, Iran

2 Department of Mathematics, Shahr-e-Qods Branch, Islamic Azad University, Tehran, Iran automobile industry. The congestion in the Chinese industry was re-examined by Jahanshahloo and Khodabakhshi [9]; the proposed models create the evaluation principles for the DMUs .Tons and Saho [12] proposed a nonparametric process in order to measure the scale of production-congestion [5]. Cooper examined congestion under a stochastic DEA using chance programming. Odeck [11] discussed the impact of congestion on inputs, such as fuel consumption, along with the impact of the number of workers in the bus industry in Norway. In his article [13] such congestion is investigated with constant returns to scale output-oriented models. Nora et al. [10] presented a new method for calculating the amount of congestion.

So far, conceptual congestion has been localized so that each unit should be examined separately, which is very timeconsuming and requires solving programming models. But the introduction of the congestion hyperplane is a linear criterion that calculates the congestion of each unit without solving any model. Since efficient units are the basis for introducing this hyperplane, it can always be introduced without using any loops. So the process of finding the hyperplane will be a linear and always convergent approach. There was no way to determine the congestion border until now. This congestion border makes it possible to recognize congestion from technical inefficiency. While congestion border helps to comprehensively identify congestion units and their amounts, previous methods could recognize congestion in evaluating 
congestion units. Sometimes, the amount of congestion in such units has been found to be zero because of nonconsideration of the convexity condition. For solving all these problems and reducing computation, the congestion hyperplane is introduced and hence congestion is not recognized as a technical inefficiency anymore. The congestion amount of congestion units is determined by the distance between points on the right-hand side of the hyperplane (right points) and the hyperplane, while threshold congestion is defined by the distance between left points and the hyperplane.

In this paper, we first introduce the methods of Cooper et al. [3] and Nora et al. [10] in "Background" section. The existence of the congestion hyperplane is ascertained by some theorems in "Proposed method" section. In "Numerical example" section, we propose a congestion hyperplane based on a linear method by using efficient units, which can separate congestion units from other DMUs. This hyperplane improves the model developed by Nora et al. [10], and the results are similar to those derived from the model of Cooper et al. [3]. Different numerical examples are selected out of two articles $[3,10]$ and then solved with the proposed method. Then, these values are compared with the previous methods. In the end, the results of this study are presented in "Conclusions" section.

\section{Background}

\section{Basic concepts}

\section{BCC model}

If $T_{v}=\left\{(x, y) \mid x \geq \sum_{i=0}^{n} \lambda_{j} x_{j}, y \leq \sum_{j=1}^{n} \lambda_{j} y_{j}, \sum_{j=1}^{n} \lambda_{j}=1, \lambda_{j} \geq\right.$ $0, j=1, \ldots, n\}$, then to measure the relative efficiency of each DMU in the output oriented, the following model should be solved:

$$
\begin{array}{ll}
\operatorname{Max} & \varphi \\
\text { s.t. } & \left(x_{o}, \varphi y_{o}\right) \in T_{V}
\end{array}
$$

$\mathrm{BCC}$ model (1) is:

$$
\begin{aligned}
& \varphi^{*}=\operatorname{Max} \varphi+\varepsilon\left(\sum_{r=1}^{s} s_{r}^{+}+\sum_{i=1}^{m} s_{i}^{-}\right) \\
& \text {s.t } \sum_{j=1}^{n} x_{i j} \lambda_{j}+s_{i o}^{-}=x_{i o}, \quad i=1,2, \ldots m \\
& \sum_{j=1}^{n} y_{r j} \lambda_{j}-s_{r o}^{+}=\varphi_{o} y_{r o}, \quad r=1,2, \ldots, s \\
& \sum_{j=1}^{n} \lambda_{j}=1 \\
& \left(\lambda_{j}, s_{i o}^{-}, s_{r o}^{+}\right) \geq 0, \quad j=1,2, \ldots, n, \quad i=1,2, \ldots, m, \quad r=1,2, \ldots, s
\end{aligned}
$$

\section{Hyperplane}

The result of solving the multiplicative models is to find the weights such as $\left(U^{*}, V^{*}\right)$ for the inputs and outputs of the unit. Given the constraints, we have a multiplicative form $U^{t} Y_{j}-V^{t} X_{j} \leq 0 ; j=1,2, \ldots, n$. In other words, the $\mathrm{n}$ hyperplanes are available with 1 gradient vector $(U, V)$.

\section{Congestion}

There is a congestion if the decrease in one or more inputs is accompanied by an increase in one or more outputs (congestion in the input), without the other inputs and outputs getting worse or vice versa, if the increase in one or more inputs along with a decrease in one or multiple outputs without getting worse in other inputs and outputs.

\section{Introducing the Cooper's method}

In this section, the method of Cooper et al. [3] and their definition of congestion will be explained. Consider that there are $\mathrm{n}$ DMUs that they have $\mathrm{m}$ inputs and s outputs. The $x_{j}=\left(x_{1 j}, x_{2 j}, \ldots, x_{m j}\right)^{T}$ and $y_{j}=\left(y_{1 j}, y_{2 j}, \ldots, y_{s j}\right)^{T}$ are the input and output vectors of $\mathrm{DMU}_{j} j=1,2, \ldots, n$, respectively.

First, they solved the output-oriented BCC (Banker, Charnes, Cooper) [1] model and then the efficiency of each DMU was obtained by solving BCC model (1).

In the above method, inefficiency is a necessary condition for the presence of congestion, and they first determined inefficient units with Model (1) and finally presented the following model to calculate the amount of congestion:

$$
\begin{aligned}
& \varphi^{*}=\max \varphi+\varepsilon\left(\sum_{r=1}^{s} s_{r}^{+}-\varepsilon \sum_{i=1}^{m} s_{i}^{-c}\right) \\
& \text { s.t } \sum_{j=1}^{n} x_{i j} \lambda_{j}+s_{i o}^{-c}=x_{i o}, \quad i=1,2, \ldots m \\
& \sum_{j=1}^{n} y_{r j} \lambda_{j}-s_{r o}^{+}=\varphi_{o} y_{r o}, \quad r=1,2, \ldots, s \\
& \sum_{j=1}^{n} \lambda_{j}=1 \\
& \left(\lambda_{j}, s_{i o}^{-c}, s_{r o}^{+}\right) \geq 0, \quad j=1,2, \ldots, n, \quad i=1,2, \ldots, m, \quad r=1,2, \ldots, s
\end{aligned}
$$

Model (1) is solved for all units to identify inefficient DMUs, but Model (2) is used to determine the congestion of inefficient units. Pay attention to the input slack. In practice, the calculations should be conducted in three stages and three models must be solved to get the optimal solution as well as to determine the amount of congestion. 
Cooper et al. [3] expressed the following definition to determine congestion in a DMU.

Definition 1 A DMU has congestion if and only if in an optimal solution $\left(\varphi^{*}, \lambda^{*}, S^{+*}, S^{-c *}\right)$ of Model (2), at least one of the following two conditions is occurred:

1. $\varphi^{*}>1$, and there exists at least one $s_{i}^{-c *}>0(1 \leq i \leq m)$.

2. There should be at least one $s_{r}^{+*}>0(1 \leq r \leq s)$ and at least one $s_{i}^{-c *}>0(1 \leq i \leq m)$.

\section{Introducing Nora's method}

First, they solved Model (1) for all DMUs and denoted the optimal solution $\left(\varphi^{*}, \lambda^{*}, S^{+*}, S^{-*}\right)$ each DMU; then, they defined Set EF as follows:

$\mathrm{EF}=\left\{j \mid \varphi^{*}=1\right\}$ or $\mathrm{EF}=\{\mathrm{BCC}$ efficient units $\}$

There exists at least one DMU, says DMUl in EF set, that has the highest value in its first input component compared to the first input component of the remaining DMUs of Set EF. That is to say:

$\exists(K \in \mathrm{EF}) \mathrm{s.t}: \forall j(j \in \mathrm{EF}) \rightarrow x_{1 K}>x_{1 j}$

They delineated $x_{1 K}$ by $x_{1}^{*}$. For all input components $(i=1$, $\ldots, m)$, they introduced a DMU in EF that $i$ th input is higher than those of all other DMUs in the set and shown by $x_{i}^{*}, i=1,2, \ldots, m$ similarly. Then, the defined congestion is as follows:

Definition 2 ADMU has congestion if and only if, in an optimal solution $\left(\varphi^{*}, \lambda^{*}, S^{+*}, S^{-*}\right)$ of Model (1) for this DMU, at least one of the following two conditions is occurred:

1. $\varphi^{*}>1$, and there exists at least one $x_{i o}>x_{i}^{*}(1 \leq i \leq m)$.

2. There is at least one $s_{r}^{+*}>0(1 \leq r \leq s)$ and at least one $x_{\text {io }}>x_{i}^{*}(1 \leq i \leq m)$.

where $x_{i o}>x_{i}^{*}$; they show the amount of congestion in the $i$ th input of DMUo by $s_{i}^{c^{\prime}}$ and it is defined as follows:

$s_{i}^{c^{\prime}}=x_{i o}-x_{i}^{*}$

A DMU has no congestion when $x_{i o} \leq x_{i}^{*}$ and $s_{i}^{c^{\prime}}=0$.

\section{Proposed method}

In this section, we prove the existence of the congestion hyperplane. In other words, there is a boundary that divides the possible production set (PPS) units into two sections: congestion units and units without congestion (noncongestion units). These two sets have no intersection. Assume that $T$ is the set of congestion units defined by Cooper et al. [3] and $T^{\prime}$ is the set of noncongestion units, according to this definition.

Theorem $1 T$ and $T^{\prime}$ sets are convex, $T$ is the set of congestion units, and $T^{\prime}$ is the set of noncongestion units defined by Cooper et al. [3].

Proof We consider two arbitrary units to prove that Set $T$ is convex:

1. If both these DMUs are efficient.

Now, we show that any convex combination of these two members of Set $T$ will belong to $T$. It means:

$\forall\left(x_{1}, y_{1}\right),\left(x_{2}, y_{2}\right) \in T,\left(\lambda x_{1}+(1-\lambda) x_{2}, \lambda y_{1}+(1-\lambda) y_{2}\right) \in T$, suppose that:

$\mathrm{DMU}_{1}=\left(x_{1}, y_{1}\right)=\left(x_{11}, x_{12}, \ldots, x_{1 m}, y_{11}, y_{12}, \ldots, y_{1 s}\right)$

$\mathrm{DMU}_{2}=\left(x_{2}, y_{2}\right)=\left(x_{21}, x_{22}, \ldots, x_{2 m}, y_{21}, y_{22}, \ldots, y_{2 s}\right)$

According to Definition 1 of congestion, if a DMU is efficient, then there is a component greater than zero in congestion slack and excess slack vectors. Thus, we consider that these components for $\mathrm{DMU}_{1}$ are $s_{1 i_{1}}^{-c *}>0, s_{1 r_{1}}^{+*}>0$, while the components for $\mathrm{DMU}_{2}$ are $s_{2 i_{2}}^{-c *}>0, s_{2 r_{2}}^{+*}>0$. Now, we show any convex combination of these two DMUs has congestion. In other words, there is a component greater than zero in congestion slack and the excess vectors corresponding to the convex combination of these two DMUs. The excess vectors $s_{1}^{+*}, s_{2}^{+*}$ are introduced as follows:

$s_{1}^{+*}=\left(s_{11}^{+*}, \ldots, s_{1 r_{1}}^{+*}, \ldots, s_{1 s}^{+*}\right)$ and $s_{2}^{+*}=\left(s_{21}^{+*}, \ldots, s_{2 r_{2}}^{+*}, \ldots, s_{2 s}^{+*}\right)$

Then, one of these two cases will occur:

(a) If the same components of excess vectors in these DMUs are greater than zero, then $r_{1}=r_{2}=r$. Since $s_{2 r}^{+*}>0, s_{1 r}^{+*}>0$ and $\lambda>0$ so we have $\lambda s_{1 r}^{+*}+(1-\lambda) s_{1 r}^{+*}>0$ and $\lambda s_{1}^{+*}+(1-\lambda) s_{2}^{+*}>0$.

(b) If the nonzero components of excess vectors in these DMUs are different, then $r_{1} \neq r_{2}$ : 


$$
\begin{aligned}
\lambda s_{1}^{+*}+(1-\lambda) s_{2}^{+*}= & \lambda\left(0, \ldots, s_{1 r_{1}}^{+*}, 0, \ldots . .0\right) \\
& +(1-\lambda)\left(0, \ldots ., s_{2 r_{2}}^{+*}, 0, \ldots . .0\right) \\
= & \left(0, \ldots, \lambda s_{1 r_{1}}^{+*}, 0, \ldots,(1-\lambda) s_{2 r_{2}}^{+*}, 0, \ldots, 0\right)>0 .
\end{aligned}
$$

So if $s_{2 r_{2}}^{+*}>0, s_{1 r_{2}}^{+*}>0$, then $\lambda s_{1}^{+*}+(1-\lambda) s_{2}^{+*}$ should be greater than zero. As the same way, we can prove that if $s_{1 i_{1}}^{-c *}, s_{2 i_{2}}^{-c *}>0\left(1 \leq i_{1}, i_{2} \leq m\right)$, then $\lambda s_{1}^{-*}+(1-\lambda) s_{2}^{-*}$ should be greater than zero. Therefore, if both of these DMUs will be efficient, then $T$ is convex. So:

2. If both these DMUs are inefficient, then they have a nonzero component in their congestion slack vectors. In this case (according to the previous section), the congestion slack of a convex combination of these DMUs has at least a nonzero component and hence this combination will be in Set $T$.

2. If $D M U_{1}$ is efficient and $\mathrm{DMU}_{2}$ is inefficient, then their convex combination will be inefficient, while the congestion slack and excess slack vectors of $\mathrm{DMU}_{2}$ will have at least a nonzero component like $s_{2 i_{2}}^{-*}>0, s_{2 r_{2}}^{+*}>0$ and the congestion slack vector of $\mathrm{DMU}_{1}$ has $s_{1 i_{1}}^{-*}>0$. Thus, based on the above proof $\lambda s_{1}^{-*}+(1-\lambda) s_{2}^{-*}$ will be greater than zero.

So in per case, $\left(\lambda x_{1}+(1-\lambda) x_{2}, \lambda y_{1}+(1-\lambda) y_{2}\right)$ has congestion and $T$ will be convex. Similarly, it can be shown that $T^{\prime}$ is convex.

Theorem $2 T$ and $T^{\prime}$ sets have no intersection where $T$ is the set of congestion units and $T^{\prime}$ is the set of noncongestion units defined by Cooper et al. [3].

Proof Suppose $T \cap T^{\prime} \neq \emptyset$. Thus, there is $\mathrm{DMU}_{o}$ as a member of $T$ and $T^{\prime}$. According to the assumption, if $\mathrm{DMU}_{o}$ is an efficient congestion unit, then the congestion slack and excess slack vectors have components greater than zero and this is in contradiction with $\mathrm{DMU}_{o} \in T^{\prime}$. And also if $\mathrm{DMU}_{o}$ is inefficient, we will reach a contradiction and hence this assumption is false.

Theorem 3 If $T$ and $T^{\prime}$ are convex and $T \cap T^{\prime}=\emptyset$, then there is a hyperplane that divides PPS into these sets.

Proof Assume Set $S$ is the difference between $T$ and $T^{\prime}$ as follows:

We first show the Set $S$ is convex. According to the definition of the $S$ : $\left\{\begin{array}{l}\left(t_{1}, t_{2}\right) \in S \rightarrow\left(t_{1}, t_{2}\right)=\left(X_{1}-X_{2}, Y_{1}-Y_{2}\right) \rightarrow\left\{\begin{array}{l}\left(X_{1}, Y_{1}\right) \in T \\ \left(X_{2}, Y_{2}\right) \in T^{\prime}\end{array}\right. \\ \left(z_{1}, z_{2}\right) \in S \rightarrow\left(z_{1}, z_{2}\right)=\left(X_{3}-X_{4}, Y_{3}-Y_{4}\right) \rightarrow\left\{\begin{array}{l}\left(X_{3}, Y_{3}\right) \in T \\ \left(X_{4}, Y_{4}\right) \in T^{\prime}\end{array}\right.\end{array}\right.$

So:

$\left(\lambda t_{1}+(1-\lambda) z_{1}, \lambda t_{2}+(1-\lambda) z_{2}\right)$

$=\left(\lambda\left(X_{1}-X_{2}\right)+(1-\lambda)\left(X_{3}-X_{4}\right)\right.$,

$\left.\lambda\left(Y_{1}-Y_{2}\right)+(1-\lambda)\left(Y_{3}-Y_{4}\right)\right)$,

According to Theorem $1, T$ and $T^{\prime}$ are convex so every combination of their members will be in Set $S$. Namely,

$\left\{\begin{array}{l}\lambda\left(X_{1}-Y_{1}\right)+(1-\lambda)\left(X_{3}-Y_{3}\right) \in T \\ \lambda\left(X_{2}-Y_{2}\right)+(1-\lambda)\left(X_{4}-Y_{4}\right) \in T^{\prime}\end{array}\right.$

$\left(\lambda t_{1}+(1-\lambda) z_{1}, \lambda t_{2}+(1-\lambda) z_{2}\right) \in S$ and $S$ is a convex set and $(0,0) \notin S$ because of $T \cap T^{\prime}=\emptyset$. Therefore, there is a hyperplane relying on a convex set:

$\exists 0 \neq P=\left(P_{1}^{t}, P_{2}^{t}\right):\left(P_{1}^{t}, P_{2}^{t}\right)(X, Y)=0$

Therefore, the existence of the congestion hyperplane was proven.

\section{The presentation of congestion hyperplane}

In this section, we introduce the congestion hyperplane. For this purpose, we determine the BCC-efficient DMUs and then define the maximum value of the input components among these DMUs. The normal vector of the hyperplane is denoted by these values. This hyperplane can pass from any of the BCC-efficient DMUs.

First we solve Model (1) for $\operatorname{DMU}_{j}(j=1,2, \ldots, n)$ and determine the optimal solution $\left(\varphi^{*}, \lambda^{*}, S^{+*}, S^{-*}\right)$. Then, Set EF is defined as follows:

$\mathrm{EF}=\left\{j \mid \varphi^{*}=1\right\}$ or $\mathrm{EF}=\{\mathrm{BCC}$ efficient units $\}$

There is a DMU in Set EF (that is called DMUI), and this DMU in the first component has the highest amount than other efficient DMUs in Set EF. It is shown as follows:

$\exists(l \in E F)$ s.t $\quad \forall j(j \in E F) \rightarrow x_{1 l}>x_{1 j}$

Then, we determine $x_{1 l}$ with $x_{1}^{*}$. Now we solve Model (3) to find all $x_{i}^{*}, i=1,2, \ldots, m$. We introduce $E^{*}$ as follows:

$\forall 1 \leq i \leq m, \quad \exists(l \in \mathrm{EF}) \mathrm{s.t}: \forall j(j \in \mathrm{EF}) \rightarrow x_{i l}>x_{i j} \rightarrow l \in \mathrm{EF}^{*}$

In other words, a BCC-efficient DMU is the $i$ th component of $\mathrm{EF}^{*}$, and its $i$ th input is higher than other efficient DMUs. We show this DMU as DMU* ${ }_{i}^{*}$. Now, suppose 
DMUk $\in \mathrm{EF}^{*}$ has the highest amount in the $k$ th input component in Set EF and its input and output vectors are $X_{k}=\left(x_{1 k}, x_{2 k}, \ldots, x_{k}^{*}, \ldots, x_{m k}\right)$ and $Y_{k}=\left(y_{1 k}, y_{2 k}, \ldots, y_{s k}\right)$, respectively. There is a hyperplane parallel to axis outputs that passes through DMUk. The normal vector of this hyperplane will be obtained by solving the following system of $m+2$ equations and $m$ unknowns. Consider that the input vector of DMU with the highest value of a first input component $\left(\mathrm{DMU}_{1}^{*}\right)$ is $X_{1}^{*}=\left(x_{1}^{*}, x_{12}, \ldots, x_{1 m}\right)$, while $X_{2}^{*}=\left(x_{21}, x_{2}^{*} \ldots, x_{2 m}\right)$ is input vector of a DMU with the highest value in the second input component $\mathrm{DMU}_{2}^{*}$. Similarly, $X_{m}^{*}=\left(x_{m 1}, x_{m 2}, \ldots, x_{m}^{*}\right)$ is the input vector of a DMU with the highest value of the $m$ th input's component, that is called $\mathrm{DMU}_{m}^{*}$.

$$
\left\{\begin{array}{c}
N\left(X_{1}^{*}-X_{k}^{*}\right)=0 \\
N\left(X_{2}^{*}-X_{k}^{*}\right)=0 \\
\vdots \\
N\left(X_{k-1}^{*}-X_{k}^{*}\right)=0 \\
\vdots \\
N\left(X_{m}^{*}-X_{k}^{*}\right)=0 \\
N .1=1 \\
N>0
\end{array}\right.
$$

Suppose that the hyperplane passes through $\mathrm{DMU}_{k}^{*} \in \mathrm{EF}^{*}$. By using the values obtained from Model (5), this congestion hyperplane is:
Proof We consider $\mathrm{DMU}_{\mathrm{o}}$ as a congestion unit. Suppose that the $k$ th congestion slack component of DMUo is greater than zero $\left(s_{i}^{-c}>0\right)$. Hence, based on the method of Cooper et al. [3], there is a Constraint (a) as well:

$\sum_{j=1}^{n} \lambda_{j}^{*} x_{k j}<x_{k o}$

Nora et al. [10] proved that $x_{i}^{*}=\sum_{j=1}^{m} \lambda_{j}^{*} x_{i j}, i=1, \ldots, m$. So we have:

$x_{k o}-x_{k}^{*}>\sum_{j=1}^{m} \lambda_{j}^{*} x_{k j}-\sum_{j=1}^{m} \lambda_{j}^{*} x_{k j}=0 \rightarrow x_{k o}-x_{k}^{*}>0, \quad i=k$.

$$
\begin{gathered}
x_{i o}-x_{i}^{*} \geq \sum_{j=1}^{m} \lambda_{j}^{*} x_{i j}-\sum_{j=1}^{m} \lambda_{j}^{*} x_{i j}=0 \rightarrow x_{i o}-x_{i}^{*} \geq 0, \\
i=1,2, \ldots, m, \quad i \neq k .
\end{gathered}
$$

The hyperplane normal vector is greater than zero, so all of its components are positive. As a result, we have:

$$
\sum_{\substack{i=1 \\ i \neq k}}^{m} n_{i}\left(x_{i o}-x_{i k}\right)+n_{k}\left(x_{k o}-x_{k}^{*}\right)>0
$$

$H=\left\{\left(\begin{array}{c}x \\ y\end{array}\right) \mid n_{1}\left(x_{1 j}-x_{1 k}\right)+\cdots+n_{m}\left(x_{m j}-x_{m k}\right)+0\left(y_{1 j}-y_{1 k}\right)+\cdots+0\left(y_{s j}-y_{s k}\right)=0\right\}$

In other words, hyperplane equation will be as follows:

$H=\left\{\left(\begin{array}{c}x \\ y\end{array}\right) \mid \sum_{\substack{i=1 \\ i \neq k}}^{m} n_{i}\left(x_{i j}-x_{i k}\right)+n_{k}\left(x_{k j}-x_{k}^{*}\right)+\sum_{r=1}^{s} 0\left(y_{r j}-y_{r k}\right)=0\right\}$

Now, with a proposition we show a congestion unit based on Definition 1 (Cooper et al. [3]) will satisfy Constraint (8). In fact, a congestion unit at the method of Cooper et al. [3] will have congestion with the proposed model.

Theorem 4 If the following condition is satisfied, then $\mathrm{DMU}_{j}(j=1,2, \ldots, n)$ has congestion:

$$
\sum_{i=1}^{m} n_{i}\left(x_{i j}-x_{i k}\right)+n_{k}\left(x_{k j}-x_{k}^{*}\right)>0
$$

Note that if the hyperplane passes from each efficient units of $\mathrm{EF}^{*}$, the distance of DMU from the congestion hyperplane will not be changed.

Definition 3 The congestion amount on each DMU is the distance from the congestion hyperplane to this DMU. In other words, if the congestion's amount of $\mathrm{DMU}_{j}$ in $i$ th input component is shown as $s_{i}^{\prime \prime}$, then $x_{i j}-s_{i}^{\prime \prime}$ must be on the congestion hyperplane. 
If all $X_{i}^{*}(i=1,2, \ldots, m)$ should not be exclusive, then we select among them $m$, different DMUs. If there are not $\mathrm{m}$ different $\mathrm{DMU}_{i}^{*}(i=1,2, \ldots, m)$, then there exist more than one congestion hyperplane.

\section{Numerical example}

In this section, the proposed model will test with selected numerical examples that had been studied by other papers.

\section{Explaining example}

(a) Consider eight DMUs with one input and one output as $A, B, C, D, E, F, G$ and $H$. These DMUs are shown in Fig. 1. The horizontal axis identifies the input and the vertical axis of the output.

(b) This example was solved by Cooper et al. [3] using Model (2), the results of which are provided in Table 1.

We now apply our proposed method to solve the same problem. Considering the efficiency of DMUs, we have Set $\mathrm{EF}=\{A, B, C\}$, where (2) becomes:

$X^{*}=X_{c}=3>x_{j}(\forall j:(j \in \mathrm{EF})) \rightarrow c \in \mathrm{EF}^{*}$
- According to the proposed model, the congestion hyperplane is $X_{j}-X^{*}=0$. We examine the condition of each DMU to the congestion hyperplane:

$$
\left\{\begin{array}{l}
A: 1-3=-2<0 \\
B: 2-3=-1<0 \\
C: 3-3=0 \\
D: 5-3=2>0 \\
E: 4-3=1>0 \\
F: 4-3=1>0 \\
G=4.5-3=1.5>0 \\
H: 3-3=0
\end{array}\right.
$$

. According to the results and Definition 2, the $D, E, F$, $G$ units are congestion DMUs because $X_{j}-X^{*}>0$ and $X_{j}-X^{*}$ in other DMUs is less than or equal to zero and hence these DMUs have no congestion. In addition, as Table 1 shows, the points D, E, F and G in Cooper et al. [3] are also congestion DMUs. The congestion amounts are shown in Table 2.

(c) Consider the six DMUs as $A, B, C, D, G$ and $R$, in Fig. 2. Each DMU has two inputs and one output. The value of output for $R$ is $y=10$, and the output of other
Fig. 1 Numerical example (a). Source: Cooper et al. [3]

Table 1 The results of the Cooper's method [3]

Table 2 The results of the proposed model

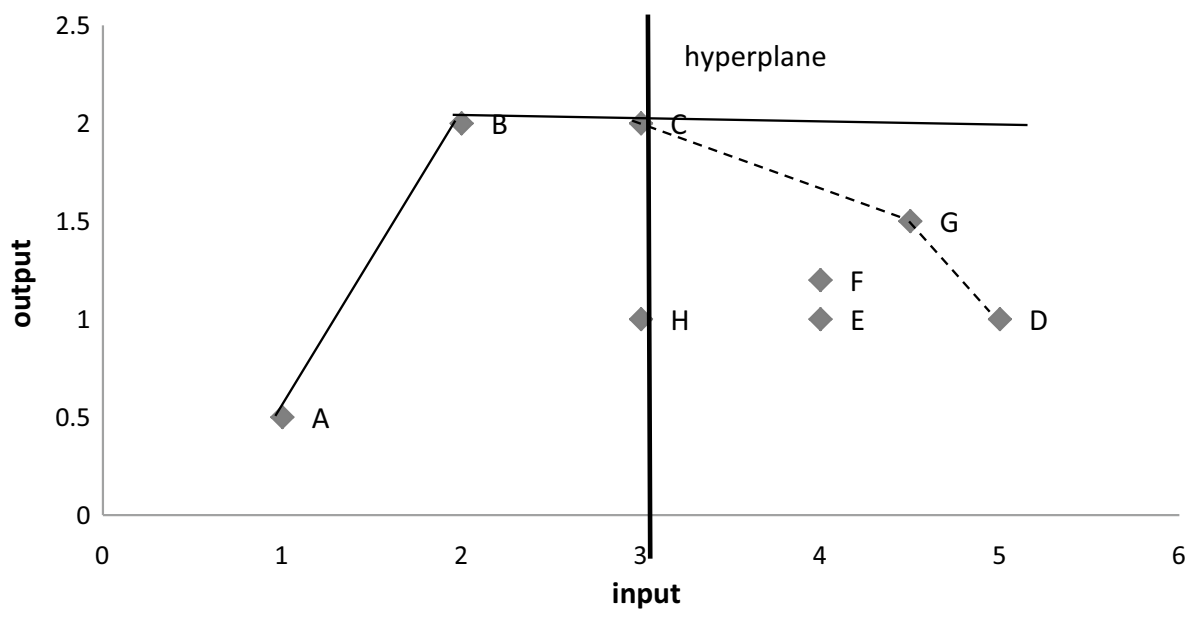

\begin{tabular}{lllllllll}
\hline DMU & A & B & C & D & E & F & G & H \\
\hline$\varphi^{*}$. & 1 & 1 & 1 & 2 & 2 & 1.667 & 1.667 & 2 \\
$S^{+*}$. & 0 & 0 & 0 & 0 & 0 & 0 & 0 & 0 \\
$S^{-*}$ & 0 & 0 & 0 & 2 & 1 & 1 & 1.5 & 0 \\
\hline
\end{tabular}

\begin{tabular}{lllllllll}
\hline DMU & A & B & C & D & E & F & G & H \\
\hline$s^{\prime \prime c}$ & 0 & 0 & 0 & 2 & 1 & 1 & 1.5 & 0 \\
\hline
\end{tabular}


Fig. 2 Numerical example 2. Source: Cooper et al. [3]

\section{CHART TITLE}

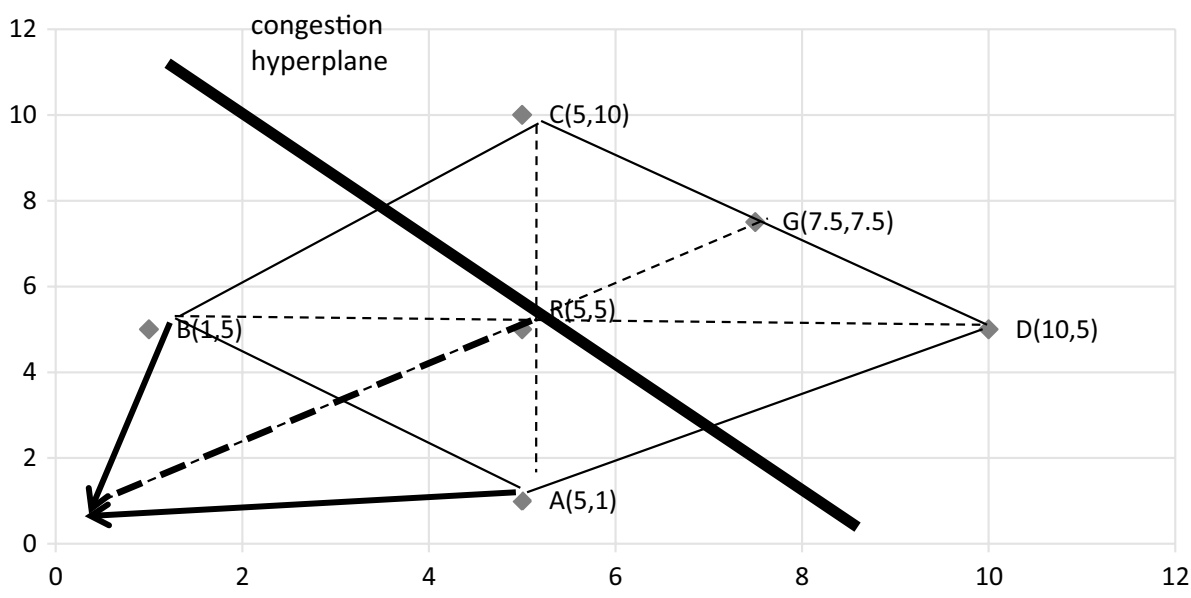

Table 3 The result of Cooper's method [3]
Table 4 The result of the proposed model

\begin{tabular}{lllllll}
\hline DMU & $A$ & $B$ & $C$ & $D$ & $G$ & $R$ \\
\hline$s_{1}^{\prime \prime}$ & 0 & 0 & 0 & 5 & 2.5 & 0 \\
$s_{2}^{\prime \prime}$ & 0 & 0 & 5 & 0 & 2.5 & 0 \\
\hline
\end{tabular}

As can be seen, the points $C, D$ and $G$ have congestion that corresponds to the results of the model developed by Cooper et al. [3]. This result is presented in Table 3.

The congestion value of Definition 3 in these DMUs states is given in Table 4:

As can be seen, the results are similar to Cooper et al. [3].

\section{Applied example}

In Table 5, data set for the Chinese automobile and textile industries during the period 1981-1997 is listed that is used by Cooper et al. [3]. The outputs and inputs are defined as follows:

$Y$ is the output measured in units of one million Renminbi, in 1991 prices; $K$ is capital calculated in units of one million Renminbi, also in 1991 prices; and $L$ is labor measured in units of 1000 persons.

All results obtained by using Model (1) are shown in Table 6. Now we solve this example by using our proposed method. For the textile industry, we have:

$\left\{\begin{array}{l}A:-2<0 \\ B:-2<0 \\ C: \frac{5}{2}>0 \\ D: \frac{5}{2}>0 \\ G: \frac{5}{2}>0 \\ R: 0\end{array}\right.$ 
Table 5 Input and output data from the textile and automobile industries of China (19811997) [3]
Table 6 DEA results using Model (1) for the textile ( $T$ ) and automobile $(A)$ industries in China

\begin{tabular}{lllrrrr}
\hline DMU & Textile $L$ & Textile $K$ & Textile $Y$ & Auto $L$ & Auto $K$ & Auto $Y$ \\
\hline DMU $_{1}=1981$ & 389.00 & 19.86 & 856.02 & 90.43 & 3.81 & 70.47 \\
DMU $_{2}=1982$ & 412.30 & 21.16 & 866.85 & 94.28 & 4.13 & $82.07+$ \\
DMU $_{3}=1983$ & 423.50 & 17.08 & 956.04 & 104.66 & 5.56 & 117.78 \\
DMU $_{4}=1984$ & 417.30 & 18.10 & 1082.94 & 121.24 & 9.50 & 168.29 \\
DMU $_{5}=1985$ & 570.00 & 12.61 & 1273.20 & 140.72 & 21.44 & 273.99 \\
DMU $_{6}=1986$ & 600.50 & 13.45 & 1230.72 & 129.08 & 20.95 & 212.89 \\
DMU $_{7}=1987$ & 641.10 & 15.91 & 1410.66 & 134.83 & 30.99 & 273.19 \\
DMU $_{8}=1988$ & 715.30 & 23.72 & 1728.16 & 150.58 & 41.29 & 407.29 \\
DMU $_{9}=1989$ & 736.00 & 25.97 & 2109.57 & 157.07 & 37.88 & 481.02 \\
DMU $_{10}=1990$ & 745.00 & 18.24 & 2291.08 & 156.53 & 41.30 & 492.49 \\
DMU $_{11}=1991$ & 756.00 & 14.40 & 2533.27 & 170.39 & 58.93 & 704.48 \\
DMU $_{12}=1992$ & 743.00 & 17.50 & 2899.16 & 184.87 & 102.75 & 1191.05 \\
DMU $_{13}=1993$ & 684.00 & 25.08 & 3520.74 & 193.26 & 164.27 & 1792.00 \\
DMU $_{14}=1994$ & 691.00 & 25.45 & 4949.93 & 196.88 & 198.77 & 2183.10 \\
DMU $_{15}=1995$ & 673.00 & 29.35 & 4604.00 & 195.25 & 231.34 & 2530.87 \\
DMU $_{16}=1996$ & 634.00 & 23.05 & 4722.29 & 195.06 & 194.90 & 2399.09 \\
DMU $_{17}=1997$ & 596.00 & 25.02 & 4760.28 & 197.81 & 203.96 & 2668.69 \\
\hline
\end{tabular}

\begin{tabular}{lcrllllll}
\hline $\mathrm{DMU}$ & $T \varphi^{*}$ & \multicolumn{1}{c}{$T S_{1}^{-*}$} & $T S_{2}^{-*}$ & $T S^{+*}$ & $A \varphi^{*}$ & \multicolumn{1}{c}{$A S_{1}^{-*}$} & $A S_{1}^{-*}$ & $A S^{+*}$ \\
\hline $\mathrm{DMU}_{1}=1981$ & 1.00 & 0.00 & 0.00 & 0.00 & 1.00 & 0.00 & 0.00 & 0.00 \\
$\mathrm{DMU}_{2}=1982$ & 1.49 & 0.00 & 0.72 & 0.00 & 1.00 & 0.00 & 0.00 & 0.00 \\
$\mathrm{DMU}_{3}=1983$ & 1.00 & 0.00 & 0.00 & 0.00 & 1.00 & 0.00 & 0.00 & 0.00 \\
$\mathrm{DMU}_{4}=1984$ & 1.00 & 0.00 & 0.00 & 0.00 & 1.00 & 14.73 & 0.00 & 0.00 \\
$\mathrm{DMU}_{5}=1985$ & 1.00 & 0.00 & 0.00 & 0.00 & 1.18 & 28.60 & 0.00 & 0.00 \\
$\mathrm{DMU}_{6}=1986$ & 1.34 & 0.00 & 0.00 & 0.00 & 1.48 & 17.19 & 0.00 & 0.00 \\
$\mathrm{DMU}_{7}=1987$ & 1.81 & 0.00 & 0.00 & 0.00 & 1.63 & 18.23 & 0.00 & 0.00 \\
$\mathrm{DMU}_{8}=1988$ & 2.77 & 65.39 & 0.00 & 0.00 & 1.42 & 1.42 & 0.00 & 0.00 \\
$\mathrm{DMU}_{9}=1989$ & 2.35 & 45.00 & 0.00 & 0.00 & 1.11 & 1.11 & 0.00 & 0.00 \\
$\mathrm{DMU}_{10}=1990$ & 1.53 & 43.16 & 0.00 & 0.00 & 1.17 & 1.17 & 0.00 & 0.00 \\
$\mathrm{DMU}_{11}=1991$ & 1.00 & 0.00 & 0.00 & 0.00 & 1.14 & 1.14 & 0.00 & 0.00 \\
$\mathrm{DMU}_{12}=1992$ & 1.14 & 30.72 & 0.00 & 0.00 & 1.15 & 1.15 & 0.00 & 0.00 \\
$\mathrm{DMU}_{13}=1993$ & 1.40 & 1.79 & 0.00 & 0.00 & 1.20 & 1.20 & 0.00 & 0.00 \\
$\mathrm{DMU}_{14}=1994$ & 1.00 & 0.00 & 0.00 & 0.00 & 1.19 & 1.19 & 0.00 & 0.00 \\
$\mathrm{DMU}_{15}=1995$ & 1.07 & 0.00 & 3.98 & 0.00 & 1.03 & 1.03 & 32.15 & 0.00 \\
$\mathrm{DMU}_{16}=1996$ & 1.00 & 0.00 & 0.00 & 0.00 & 1.06 & 1.06 & 0.00 & 0.00 \\
$\mathrm{DMU}_{17}=1997$ & 1.00 & 0.00 & 0.00 & 0.00 & 1.00 & 1.00 & 0.00 & 0.00 \\
\hline${ }=190$
\end{tabular}

$\mathrm{EF}_{\text {textile }}=\left\{\mathrm{DMU}_{1}, \mathrm{DMU}_{3}, \mathrm{DMU}_{4}, \mathrm{DMU}_{5}, \mathrm{DMU}_{11}, \mathrm{DMU}_{14}, \mathrm{DMU}_{16}, \mathrm{DMU}_{17}\right\}$

By comparing the efficiency score of DMUs in the textile industry, we find that $\mathrm{DMU}_{11}$ and $\mathrm{DMU}_{14}$ have the maximum input at the first and second components, respectively. Thus,

$x_{1}^{*}=x_{1,11}=756$ and $x_{2}^{*}=x_{2,14}=25.45$

For the automobile industry, we have: $x_{1}^{*}=x_{1,17}=197.8$ and $x_{2}^{*}=x_{2,17}=253.96$

The results obtained from the proposed model and Nora et al. [10] and the congestion amounts obtained based on Definition 3, $s^{\prime \prime c}$, are shown in Table 7. As can be seen, the distance of congestion DMUs from the hyperplane is 
Table 7 Congestion results of Cooper [3] and Noura [10] and the proposed method for textile $(T)$ and automobile $(A)$ industries

\begin{tabular}{|c|c|c|c|c|c|c|c|c|c|c|c|c|}
\hline DMU & $T S_{1}^{C *}$ & $T S_{2}^{C *}$ & $T S_{1}^{C^{\prime}}$ & $T S_{2}^{C^{\prime}}$ & $T(P)$ & $T S^{\prime \prime C}$ & $A S_{1}^{C *}$ & $A S_{2}^{C *}$ & $A S_{1}^{C^{\prime}}$ & $A S_{2}^{C^{\prime}}$ & $A(P)$ & $A S^{\prime \prime C}$ \\
\hline $\mathrm{DMU}_{1}=1981$ & 0.00 & 0.00 & 0.00 & 0.00 & -48.56 & 0.00 & 0.00 & 0.00 & 0.00 & 0.00 & -200.15 & 0.00 \\
\hline $\mathrm{DMU}_{2}=1982$ & 0.00 & 0.72 & 0.00 & 0.00 & -44.16 & 0.00 & 0.00 & 0.00 & 0.00 & 0.00 & -199.83 & 0.00 \\
\hline $\mathrm{DMU}_{3}=1983$ & 0.00 & 0.00 & 0.00 & 0.00 & -46.02 & 0.00 & 0.00 & 0.00 & 0.00 & 0.00 & -198.40 & 0.00 \\
\hline $\mathrm{DMU}_{4}=1984$ & 0.00 & 0.00 & 0.00 & 0.00 & -46.05 & 0.00 & 14.73 & 0.00 & 0.00 & 0.00 & -194.46 & 0.00 \\
\hline $\mathrm{DMU}_{5}=1985$ & 0.00 & 0.00 & 0.00 & 0.00 & -28.55 & 0.00 & 28.60 & 0.00 & 0.00 & 0.00 & -182.52 & 0.00 \\
\hline $\mathrm{DMU}_{6}=1986$ & 0.00 & 0.00 & 0.00 & 0.00 & -23.40 & 0.00 & 17.19 & 0.00 & 0.00 & 0.00 & -183.01 & 0.00 \\
\hline $\mathrm{DMU}_{7}=1987$ & 0.00 & 0.00 & 0.00 & 0.00 & -15.40 & 0.00 & 18.23 & 0.00 & 0.00 & 0.00 & -172.97 & 0.00 \\
\hline $\mathrm{DMU}_{8}=1988$ & 65.39 & 0.00 & 0.00 & 0.00 & 2.05 & 3.025 & 29.14 & 0.00 & 0.00 & 0.00 & -162.67 & 0.00 \\
\hline $\mathrm{DMU}_{9}=1989$ & 45.00 & 0.00 & 0.00 & 0.00 & 6.98 & 9.85 & 37.24 & 0.00 & 0.00 & 0.00 & -166.08 & 0.00 \\
\hline $\mathrm{DMU}_{10}=1990$ & 43.16 & 0.00 & 0.00 & 0.00 & 1.68 & 2.87 & 34.34 & 0.00 & 0.00 & 0.00 & -162.66 & 0.00 \\
\hline $\mathrm{DMU}_{11}=1991$ & 0.00 & 0.00 & 0.00 & 0.00 & 0 & 0.00 & 40.67 & 0.00 & 0.00 & 0.00 & -145.03 & 0.00 \\
\hline $\mathrm{DMU}_{12}=1992$ & 30.72 & 0.00 & 0.00 & 0.00 & 0.76 & 1.62 & 34.58 & 0.00 & 0.00 & 0.00 & -101.21 & 0.00 \\
\hline $\mathrm{DMU}_{13}=1993$ & 1.79 & 0.00 & 0.00 & 0.00 & -1.33 & 0.00 & 14.08 & 0.00 & 0.00 & 0.00 & -39.69 & 0.00 \\
\hline $\mathrm{DMU}_{14}=1994$ & 0.00 & 0.00 & 0.00 & 0.00 & 0 & 0.00 & 1.51 & 0.00 & 0.00 & 0.00 & -5.19 & 0.00 \\
\hline $\mathrm{DMU}_{15}=1995$ & 0.00 & 3.98 & 0.00 & 3.90 & 0.71 & 0.75 & 0.00 & 32.15 & 0.00 & 0.00 & 27.38 & 27.38 \\
\hline $\mathrm{DMU}_{16}=1996$ & 0.00 & 0.00 & 0.00 & 0.00 & -10.33 & 0.00 & 0.00 & 0.00 & 0.00 & 0.00 & -9.06 & 0.00 \\
\hline $\mathrm{DMU}_{17}=1997$ & 0.00 & 0.00 & 0.00 & 0.00 & -14.17 & 0.00 & 0.00 & 0.00 & 0.00 & 0.00 & 0 & 0.00 \\
\hline
\end{tabular}

positive, while this amount is less than or equal to zero for efficient or technically inefficient DMUs. The distance between DMU and the hyperplane with $P$ value will be shown in the following table.

\section{Discussions}

The comparison between the methods of Cooper et al. [3] and Nora et al. [10] shows the many advantages of the proposed model that should be discussed individually. According to Definition 1, congestion will occur, while increases in one or more input(s) would cause reduction in one or more output(s) without making changes in the other inputs and outputs. In other words, if we have one input and one output, the congestion can be achieved, while increases in this input cannot gain more output. Consider Unit 2 and Unit 13 in the automotive industry (Table 5). In this example, the congestion hyperplane is defined in passing from $\mathrm{DMU}_{14}$. Based on Table 3, it is clear that the input and output vectors of $\mathrm{DMU}_{2}$ are smaller than the input and output vectors of $\mathrm{DMU}_{14}$. In fact, $\mathrm{DMU}_{14}$ has been able to obtain more output by consuming more input than $\mathrm{DMU}_{2}$. Therefore, any decrease in the output of Unit 2 depends on inefficiency rather than congestion. In other words, by comparing the inputs of Unit 2 (21.16, 412.3) to those of Unit 14 , we have $(21.16,412.3)<(691$, 25.45). In addition, comparing $\mathrm{DMU}_{14}$ with $\mathrm{DMU}_{2}$ shows that $o_{\mathrm{DMU}_{14}}=4949.93>866.85=O_{\mathrm{DMU}_{2}}$. Similarly, in Unit 13, $I_{\mathrm{DMU}_{13}}=(684,25.08)<(691,25.45)=I_{\mathrm{DMU}_{14}}$ and $O_{\mathrm{DMU}_{13}}=3250.74<4949.93=O_{\mathrm{DMU}_{14}}$.

The congestion observed in Units 2 and 13, based on the model of Cooper et al. [3], is the type of inefficiency that is wrongly considered as congestion. Owing to Table 7, the results in the textile industry, and the model of Cooper et al. [3] model, $\mathrm{DMU}_{15}$ has congestion. And also, based on the model of Nora et al. [10], this unit has no congestion. But it is shown that the input vector of Unit 15 has a larger component rather than the input vector of Unit 17 . Notice that the congestion hyperplane is considered passing from Unit 17. It means that the congestion of this unit cannot be considered as technically inefficient. The model of Nora et al. [10] has considered zero congestion amount for a congestion unit (Unit 15) by ignoring the convexity condition. The model of Cooper et al. [3] introduces 4, 5, 6, 7, 8, 9, 10, 11, $12,13,14$ units as congestion units. But by comparing the input and output vectors of these units with those of Unit 17, we find that the input and output components of these units are less than those of Unit 17. Thus, based on the model of Cooper et al. [3], the inefficiency of these units is considered wrongly as the congestion. The congestion is known as a type of inefficiency, but the model of Cooper et al. [3] measured the amount of congestion in four efficient units in such a way that the proposed model solved this problem. Therefore, in some cases, the proposed model corrects the models of Nora et al. [10] and Cooper et al. [3].

\section{Conclusions}

In this paper, we have shown the existence of the congestion hyperplane by expressing some propositions. This hyperplane can make a complete separation between congestion units and efficient and technically inefficient units. Also, the normal vector has been introduced by using BCC-efficient 
units and the highest consumption input components. The congestion hyperplane not only confirms the previous models, but in some cases corrects the models incapacity to introduce the congestion border, inability to distinguish among the congestion units of technical inefficient units and disregard of the congestion units due to the lack of consideration of the convexity condition. The advantages of this proposed method are the determination of congestion units, estimation of the congestion amount by using the distance of the congestion border per unit and the specification of congestion units based on the convexity condition and considerable reduction of computation. Future research could study the creation of the hyperplane on fuzzy data and integer data.

\section{Compliance with ethical standards}

Conflict of interest The authors declare that they have no conflict of interest.

Open Access This article is distributed under the terms of the Creative Commons Attribution 4.0 International License (http://creativeco mmons.org/licenses/by/4.0/), which permits unrestricted use, distribution, and reproduction in any medium, provided you give appropriate credit to the original author(s) and the source, provide a link to the Creative Commons license, and indicate if changes were made.

\section{References}

1. Banker, R.D., Charnes, A., Cooper, W.W.: Some models for estimating technical and scale inefficient in data envelopment analysis. Manag. Sci. 30, 1078-1092 (1984)
2. Brockett, P.L., Cooper, W.W., Shin, H.C., Wang, Y.: Inefficiency and congestion in Chinese production before and after the 1978 economic reform. Socio-Econ. Plan. Sci. 32, 1-20 (1998)

3. Cooper, W.W., Deng, H., Gu, B.S., Li, S.L., Thrall, R.M.: Using DEA to improve the management of congestion in Chinese industries (1981-1997). Socio-Econ. Plan. Sci. 35, 227-242 (2001)

4. Cooper, W.W., Deng, H., Huang, Z.M., Li, S.L.: A one-model approach to congestion in data envelopment analysis. Eur. J. Oper. Res. 36(4), 231-238 (2002)

5. Cooper, W.W., Deng, H., Huang, Z., Li, S.X.: Chance constrained programming approaches to congestion in stochastic data envelopment analysis. Eur. J. Oper. Res. 155, 487-501 (2004)

6. Cooper, W.W., Gu, B.S., Li, S.L.: Comparisons and evaluation of alternative approaches to the treatment of congestion in DEA. Eur. J. Oper. Res. 132, 62-74 (2001)

7. Cooper, W.W., Seiford, L.M., Zhu, J.: A unified additive model approach for evaluating inefficiency and congestion. Socio-Econ. Plan. Sci. 34, 1-26 (2000)

8. Fare, R., Grosskopf, S., Lovell, C.A.K.: The measurement of efficiency of production. Kluwer-Nijh off Publishing, Boston (1985)

9. Jahanshahloo, G.R., Khodabakhshi, M.: Suitable combination of inputs for improving outputs in DEA with determining input congestion, considering textile industry of China. Appl. Math. Comput. 151, 263-273 (2004)

10. Noura, A.A., Hosseinzade Lotfi, F., Jahanshahloo, G.R., Fanati Rashidi, S., Parker, B.R.: A new method for measuring congestion in data envelopment analysis. Socio-Econ. Plan. Sci. 44, 240-246 (2010)

11. Odeck, J.: Congestion, ownership, region of operation, and scale: their impact on bus operator performance in Norway. Socio- Econ. Plan. Sci. 40, 52-69 (2006)

12. Tone, K., Sahoo, B.K.: Degree of scale economies and congestion: a unified DEA approach. Eur. J. Oper. Res. 158, 755-772 (2004)

13. Wei, Q.L., Yan, H.: Congestion and returns to scale in data envelopment analysis. Eur. J. Oper. Res. 153, 641-660 (2004)

Publisher's Note Springer Nature remains neutral with regard to jurisdictional claims in published maps and institutional affiliations. 